\title{
Soil Quality of Agricultural Fields in the Vicinity of Selected Mining Areas of Raniganj Coalfield India
}

\author{
Sayar Yaseen ${ }^{1}$, Amit Pal $^{2}$, Siddharth Singh ${ }^{3}$ and Bhat Mohd Skinder ${ }^{1^{*}}$ \\ ${ }^{1}$ Centre of Research for Development/Department of Environmental Science, University of Kashmir Srinagar (J\&K) India. \\ ${ }_{1,2}$ Instiute of Environment and Development Studies Bundelkhand University Jhansi (U.P) India.
}

${ }^{3}$ Central Institute of Mining and Fuel Research (CSIR) Dhanbad Jharkhand India

\begin{abstract}
The study was conducted to evaluate the soil quality and impact of coal mining operations on different physicochemical parameters of soils of paddy fields, located in the vicinity of Raniganj coalfield, India. During the entire study period, bulk density of soil ranges from 1.2 to $1.4 \mathrm{gm} / \mathrm{cc}, \mathrm{pH}$ varies from 5.2 to 7.4 , while electric conductivity fluctuated between $120-527 \mu \mathrm{s} / \mathrm{cm}$, organic carbon content and organic matter varied from 0.29 to $2.05 \%, 0.5 \%$ to $3.5 \%$ respectively. The average values of available nitrogen and phosphorus was 94.2 and $5.9 \mathrm{~kg} / \mathrm{ha}$. Statistical analysis of the data showed positive co-relation of organic carbon with parameters like $\mathrm{pH}$, electrical conductivity, organic matter, available phosphorus and available nitrogen. Bray Curtis similarity analysis shows that there is a similarity of $96.7 \%$ between Site VIII and II and $93.68 \%$ between site VI and V.
\end{abstract}

Keywords: Paddy field; Coal field; Physico-chemical parameters; Soil quality

\section{Introduction}

The exploitation and utilization of coal resources is major cause for a series of ecological and environmental problems throughout the world [1]. In the last few decades, wakeup call has come in terms of environmental problems induced by coal exploitation in mining areas along with subsequent ecological restoration has become burning issue all over the world [2-4]. Over exploitation of coal has created threat not in terms of its increase in carbon level only but it directly leads hazardous to the ecosystems of the world. Mining of coal reservoirs in India are increasing day by day it became harsh and typically damages ecosystems in various parts of the world [2]. As coal being the dominant energy source in India it is used for different uses $70 \%$ of its bulk quantity is used for thermal power production, and the remainder being used by heavy industry and public use. Besides, coal mining being one of the important activities for its exploitation it leads to adverse effects as well as in terms of degradation of soil fertility [5]. The huge amounts of mining waste materials from coal mining operations destroy soil fertility of agricultural land in their vicinity [6]. Due to this fact lot of research work has been carried out on the different aspects of coal mining in the world [7-11]. Thus, the work has been carried out in the Raniganj coal field in order to conclude the level of the impact of coal mining operations on soil fertility.

\section{Study Area}

Raniganj, the birth place of coal mining in India, is situated about $185 \mathrm{Km}$ North-West of Kolkata lying between the coordinates $23^{\circ} 37^{\prime} \mathrm{N}$ $87^{\circ} 08^{\prime} \mathrm{E}$ latitude and $23.62^{\circ} \mathrm{N}-87.13^{\circ} \mathrm{E}$ longitude and its major portion is located in the four districts of West Bengal (Burdwan, Birbhum, Purulia and Bankura) and rest of it, is located in Dhanbad district of Jharkhand (Figure 1).

\section{Geological Setting}

The Raniganj coalfield is a part of the Gondwana Super group. The Gondwana Formation here extends over an area of over $1000 \mathrm{Sq}$ $\mathrm{km}$, occupying roughly a rectangular tract. A full succession of lower Gondwana and younger rock occur here attaining a maximum thickness of more than 3200 meter. A large part of the coalfield is occupied by Barakar and Raniganj Measures. The younger sedimentaries comprising Panchet and Supra Panchet occur over a smaller area in the northern western part.

Laterites and lateritic soils are mostly concentrated in the derivational and dissected uplands. These soils are generally yellow grey colored on the top and red below and are very poor in organic matter, nitrogen, available phosphorous and calcium content. Besides, riverine alluvial soils are found along the river stretches. On the basis of depositional characteristics two types of alluvial soils can be identified -older alluviums and newer alluviums. The older alluviums are found over the levee region and on the alluvial terraces at different heights. The soils are red in color, iron stained and clayey. In the flood plains of the lower Damodar region newer alluvial soils are widely found. These newer alluvial soils cover extensive areas in Birbhum, Bankura and Burdwan districts. These soils are mostly developed on low terraces. The texture is moderately coarse; as a result the water holding capacity of the soil is low.

\section{Material and Methods}

Three mining areas were chosen in the adjoining vicinity of the coal fields and soil samples were collected by applying accurate sampling protocols. Bulk density was determined by Gravimetric method. The soil texture was determined by International pipette method. $\mathrm{pH}$ and electrical conductivity was determined in (soil/water: 1:2.5) suspension with a digital $\mathrm{pH}$ meter and conductivity meter respectively. Organic carbon was determined by using the Walkley and Blake Method [12] and the organic matter by using a conversion factor of 1.724 .

*Corresponding author: Bhat Mohd Skinder, Centre of Research for Development/ Department of Environmental Science, University of Kashmir Srinagar (J\&K), India, Tel: 919018515313; E-mail: mskbhat@gmail.com

Received September 02, 2014; Accepted January 20, 2015; Published January 24,2015

Citation: Yaseen S, Pal A Singh S, Skinder BM (2015) Soil Quality of Agricultural Fields in the Vicinity of Selected Mining Areas of Raniganj Coalfield India. J Environ Anal Toxicol 5: 269. doi:10.4172/2161-0525.1000269

Copyright: ( $\odot 2015$ Yaseen S, et al. This is an open-access article distributed under the terms of the Creative Commons Attribution License, which permits unrestricted use, distribution, and reproduction in any medium, provided the original author and source are credited. 
Citation: Yaseen S, Pal A, Singh S, Skinder BM (2015) Soil Quality of Agricultural Fields in the Vicinity of Selected Mining Areas of Raniganj Coalfield India. J Environ Anal Toxicol 5: 269. doi:10.4172/2161-0525.1000269

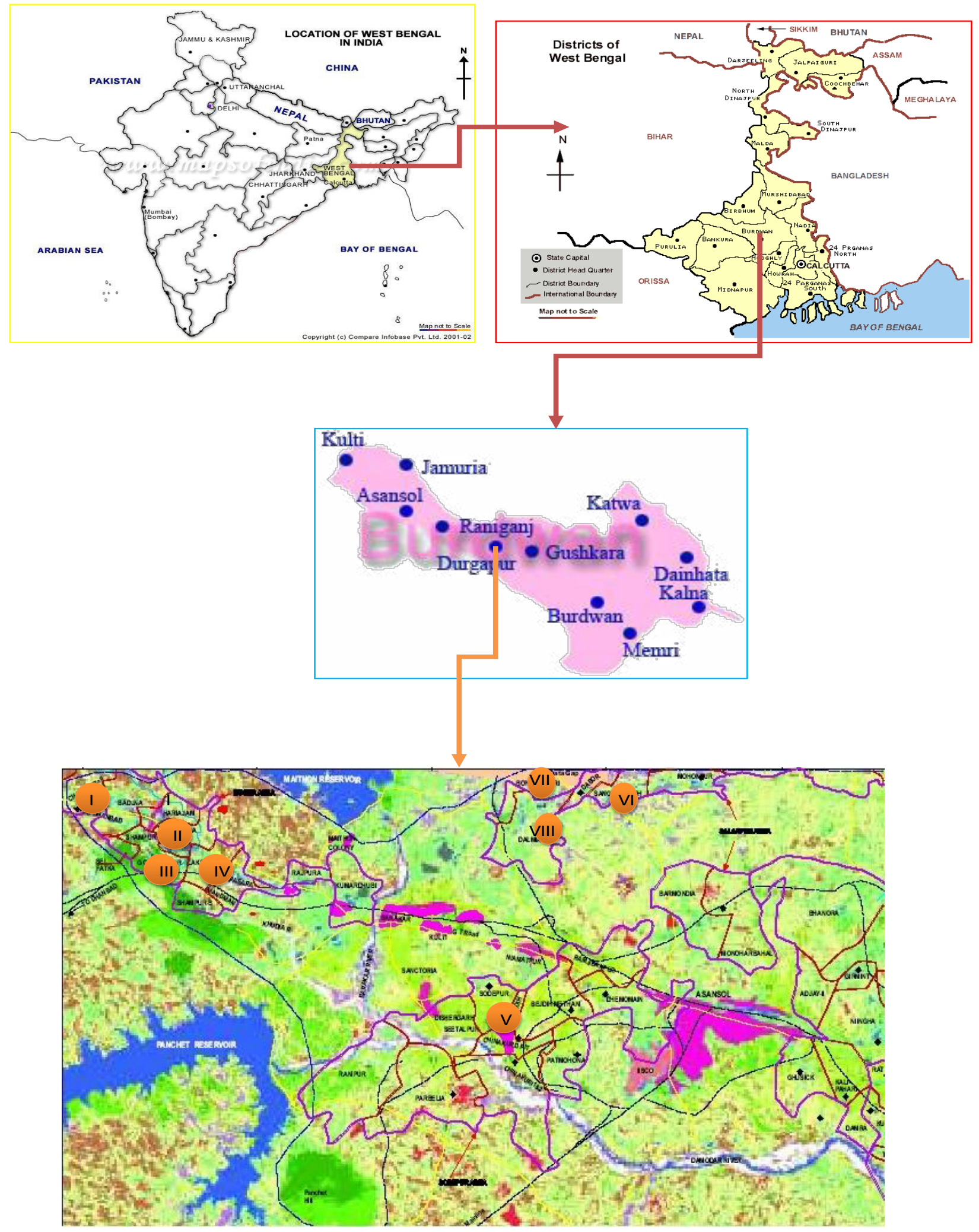

Figure 1: Location map of the Study Area Showing Sampling Sites 
Citation: Yaseen S, Pal A, Singh S, Skinder BM (2015) Soil Quality of Agricultural Fields in the Vicinity of Selected Mining Areas of Raniganj Coalfield India. J Environ Anal Toxicol 5: 269. doi:10.4172/2161-0525.1000269

Page 3 of 6

\begin{tabular}{|c|c|c|c|}
\hline Site & Name of Colliery & Mining Area & Mugma \\
\hline I & Chapapur Colliery U/G & Mugma \\
\hline II & Khasinirsa Village & Mugma \\
\hline III & Sashanberia Village & Mugma \\
\hline IV & Mugma Village & Sodepur \\
\hline V & Mouthdih Colliery U/G & Sandy Loam \\
\hline VII & Mahanpur Colliery & Salanpur \\
\hline VIII & Jangram Village & Salanpur \\
\hline
\end{tabular}

Table 1: Description of sampling sites in Raniganj coalfield

\begin{tabular}{|c|c|c|c|c|c|c|c|c|c|c|c|c|}
\hline Parameters & Units & 1 & II & III & IV & $\mathbf{V}$ & VI & VII & VIII & Min. & Max. & Avg. \\
\hline Bulk Density & (g/cc) & 1.2 & 1.3 & 1.2 & 1.3 & 1.2 & 1.4 & 1.4 & 1.4 & 1.2 & 1.4 & 1.3 \\
\hline $\begin{array}{l}\text { Moisture } \\
\text { Content }\end{array}$ & $(\%)$ & 6 & 2.7 & 6 & 4.9 & 5.2 & 2.9 & 4.4 & 1.4 & 1.4 & 6 & 4.2 \\
\hline $\mathrm{pH}$ & & 6.3 & 7.4 & 6.7 & 6.9 & 7.1 & 6.2 & 5.2 & 5.5 & 5.2 & 7.4 & 6.4 \\
\hline EC & $(\mu \mathrm{S} / \mathrm{cm})$ & 127.8 & 400.5 & 527 & 279.4 & 199.9 & 228.6 & 120.9 & 388.5 & 120.9 & 527 & 284.1 \\
\hline Organic Carbon & $(\%)$ & 0.7 & 2.1 & 1.6 & 0.6 & 1.1 & 1 & 0.3 & 0.9 & 0.3 & 2.1 & 1 \\
\hline Organic Matter & $(\%)$ & 1.2 & 3.5 & 2.8 & 1.1 & 1.9 & 1.7 & 0.5 & 1.5 & 0.5 & 3.5 & 1.8 \\
\hline $\begin{array}{l}\text { Available } \\
\text { nitrogen }\end{array}$ & kg/ha) & 93.45 & 98.64 & 90.64 & 94.78 & 90.24 & 92.45 & 97.21 & 95.68 & 98.64 & 90.24 & 94.197 \\
\hline $\begin{array}{c}\text { Available } \\
\text { Phosphorus }\end{array}$ & (kg/ha) & 3.9 & 15.5 & 8.7 & 3 & 2.4 & 2.4 & 7.4 & 4.1 & 2.4 & 15.5 & 5.9 \\
\hline $\begin{array}{l}\text { Max. water Holding } \\
\text { capacity }\end{array}$ & (\%) & 43.5 & 32.2 & 39.6 & 29.4 & 41.8 & 30.9 & 28 & 30.7 & 43.5 & 28 & 34.5 \\
\hline
\end{tabular}

Table 2: Physico-chemical Properties of the Soil Samples of Study Area

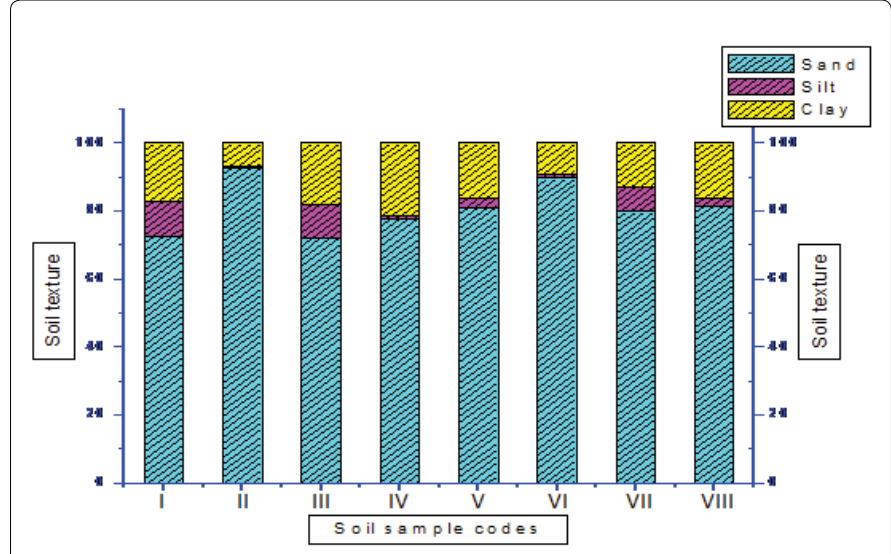

Figure 2: Graphical representation of soil texture of study sites

Available phosphorus content was determined by Olsen's Method [13]. Available Nitrogen was determined by the alkaline potassium permagnate Method [14].

\section{Results and Discussion}

The results of physicochemical analysis of soil of Raniganj Coal field (RCF) are presented in Tables 1 and 2.

\section{Bulk Density}

Bulk density is a measure of the weight of the soil per unit volume, usually given on an oven dry basis. Most minerals soils have bulk densities between $1.0 \mathrm{~g} / \mathrm{cm}^{3}$ and $2.0 \mathrm{~g} / \mathrm{cm}^{3}$ [15]. Bulk density of soil samples is quite variable from one site to another site. It also depends on the texture, soil structures and organic matter status of the soil [16]. Bulk density of soil was found to be between $1.2 \mathrm{~g} / \mathrm{cm}^{3}$ to $1.4 \mathrm{~g} / \mathrm{cm}^{3}$ with an average of $1.3 \mathrm{~g} / \mathrm{cm}^{3}$. Bulk density of soil was found lower at
Sites I, III and IV due to presence of high organic matter in the soil. Bulk density of soil was found higher at Sites VI, VII and VIII due to less amount of organic matter present in the soil system. Further bulk density shows negative correlation with maximum water holding capacity $\left(r_{-} 0.95\right)$ as shown in Figure 3 , because, soils with high bulk density have a smaller volume of pore spaces. The similar correlation has also been reported by [17].

\section{Moisture content}

Moisture content indicates the amount of water present in the soil. The moisture content of soil can be expressed in percentage. The amount of water stored in the soil is not constant with time, but may vary with time to time. Moisture content of the selected soil was found to be ranged from $1.43 \%$ to $6.015 \%$ with an average of $4.2 \%$. Moisture content of soil was found lower at Site VIII (1.43\%) due to presence of rocky mass materials and vice versa. While as it was higher at Site III (6.02\%) and Site-I (5.5\%) indicating well for normal growth of plants. This data gives an idea about the normal growth of plants in coal mining area. Besides in the later two sites there was proper irrigation facilities installed in the form of hand pumps which were used to provide the necessary water to the fields.

\section{Soil texture classes}

The soil texture was determined with help of Standard International pipette method $(<1 \mathrm{~mm}$ soil size) is given in Figure 2 and Table 3. Soil texture classes were based on varying proportions of sand, silt and clay, expressed as percentages.

In the soil samples of study area the percentage of sand, silt and clay ranges from (71.96\% to $92.81 \%),(0.14 \%$ to $10.28 \%)$ and $(7.04 \%$ to $21.28 \%$ ) with the average percentage of $80.87 \%, 4.36 \%$ and $14.76 \%$ respectively. So the main texture of soil of study area is sandy soil which is not best for agricultural soils. The intermediate loam textures 

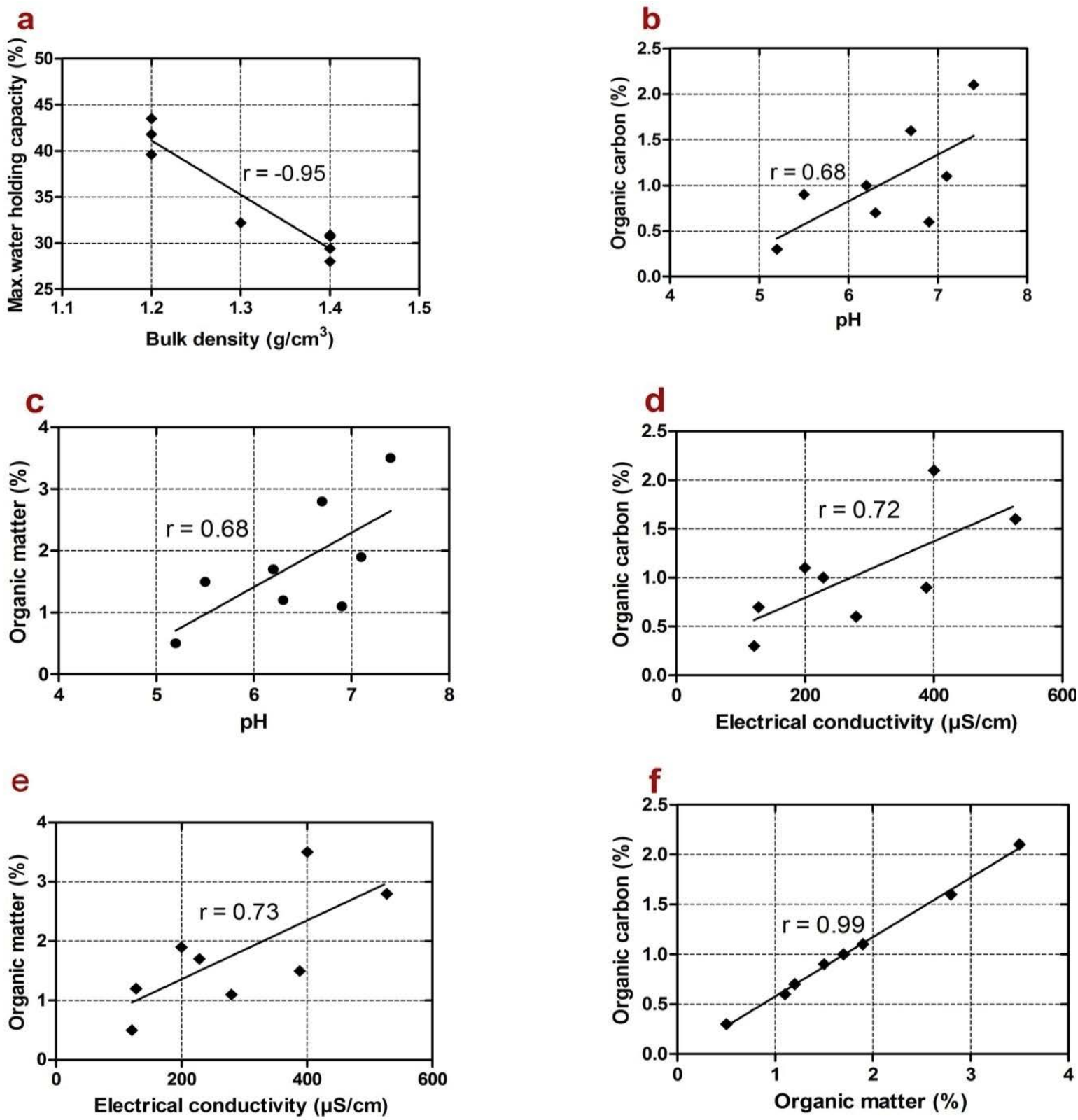

g

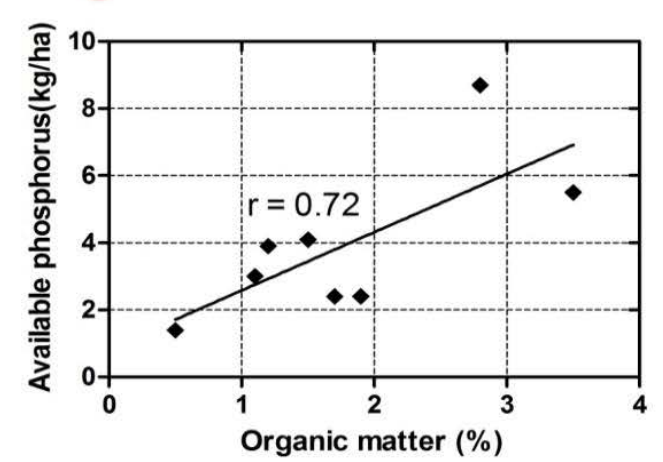

h

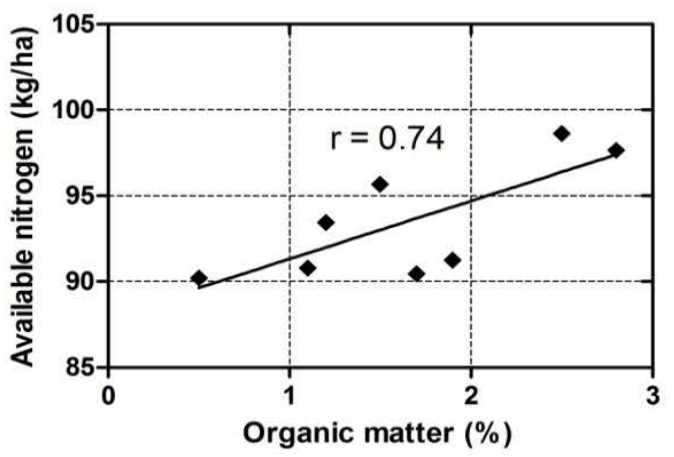

Figure 3: Scatter diagram showing positive and negative correlation between average values of physico-chemical parameters of soil. 


\begin{tabular}{|c|c|c|c|c|c|c|c|c|c|c|c|}
\hline Sample Code & I & II & III & IV & $\mathbf{v}$ & VI & VII & VIII & Average & Max. & Min. \\
\hline Sand & 72.59 & 92.81 & 71.96 & 77.6 & 80.97 & 89.72 & 79.76 & 81.56 & 80.36 & 92.81 & 71.96 \\
\hline Silt & 10.28 & 0.14 & 10.08 & 1.12 & 2.8 & 1.12 & 7.24 & 2.16 & 4.37 & 10.28 & 0.14 \\
\hline Clay & 17.13 & 7.04 & 17.96 & 21.28 & 16.24 & 9.16 & 13 & 16.28 & 14.76 & 21.28 & $7.04 \mathrm{~s}$ \\
\hline
\end{tabular}

Table 3: Soil texture of Study Area

are generally best as agricultural soils [18] reported the maximum sand content of $66 \%$ and clay only $8.6 \%$ in mined soil. The maximum content of sand $(80 \%)$ and least content of clay (11\%) have also been reported at the Singrauli Coal field India [10].

$\mathrm{pH}$ is an important index of ecological condition of terrestrial environment [19]. At greater depths $\mathrm{pH}$ is usually found to be more acidic [20]. The maximum availability of the primary nutrient like nitrogen, phosphorus and potassium as well as secondary nutrients like sulphur, calcium and magnesium are found in the $\mathrm{pH}$ range of 6.5 to 7.5 $[21,22]$. In the present study, $\mathrm{pH}$ of soil samples was found to be lower at site VII (5.2) and higher amount at site II (7.4). Low pH at the site VII can be attributed to oxidation of pyrite particles in the soil samples and high at the site II due to absence of pyrite particles in the soil samples. The desired $\mathrm{pH}$ for good vegetation ranges from 5.5 to 6.8.pH is a good measure of acidity and alkalinity of soil water suspension and it provides a good identification of soil chemical nature. The higher $\mathrm{pH}$ indicated optimal range for plant growth but lower $\mathrm{pH}$ cause problems for normal growth of the plants. Our results are in consonance with [20], while studying on the soils of Jharia coalfield in Dhanbad

Electrical conductivity (EC) is the most common measure of soil salinity and is indicative of the ability of an aqueous solution to carry an electric current. It is well established that conductivity $0.2 \mathrm{dS} / \mathrm{m}-0.8$ $\mathrm{dS} / \mathrm{m}$ is the optimal range for plant growth. Plants are affected, both physically and chemically, by excess salts in some soils and by high levels of exchangeable sodium in others [21]. During study period, EC were found to be ranged $120 \mu \mathrm{s} / \mathrm{cm}-527 \mu \mathrm{s} / \mathrm{cm}$ in different sites of Raniganj coalfield. The higher values at site VII $(527 \mu \mathrm{s} / \mathrm{cm})$ and site II $(400 \mu \mathrm{s} / \mathrm{cm})$ were due to upward migration of different salts with spontaneous combustion of coal particles in and around the sampling sites. The minimum valued observed at site III $(120 \mu \mathrm{s} / \mathrm{cm})$, and site I $(127 \mu \mathrm{s} / \mathrm{cm})$. This might be due to lower amount of different salts present in the soil samples.

Organic carbon is important parameters of soil because it improves both the physical and chemical properties of soil and has several beneficial effects on soil quality. It also improves soil structure, enhances aeration, water penetration, and increases water-holding capacity and supplies nutrients for growth of plants. Organic carbon levels greater than $0.8 \%$ is rated as good quality of soil [21], A level of organic carbon greater than $0.75 \%$ indicates good fertility [22]. The amount of soil organic carbon (SOC) depends on soil texture, climate, vegetation and historical and current land use/management. In the present study, the organic carbon content in soil samples varied from $0.29 \%$ to $2.05 \%$ in selected sampling sites of Raniganj coalfield. The organic carbon in Site VII $(0.29 \%)$ were found low due to lack of several microbes, low humification, rate, lack of weeds in the sampling sites, whereas high organic carbon were recorded at Site II (2.05\%) due to higher amount of humic substances present in the soil samples from decomposition of garbage wastes dumped on the soil and also due to addition of domestic wastes. Organic carbon level in most of the soil samples has been found poor in range. Soil texture affects Soil Organic Carbon (SOC) because of the stabilizing properties that clay has on organic matter.
Soil organic matter is a complex mixture of organic components, ranging from recent plant residues to complex products of transformation processes and including the microbial biomass. Organic matter can be trapped in the very small spaces between clay particles making them inaccessible to micro-organisms and therefore slowing decomposition Organic matter is the major source of nutrients such as nitrogen, and available $\mathrm{P}$ and $\mathrm{K}$ in unfertilized soils [23]. The Organic matter of soil in the studied areas varied between $0.5 \%$ to $3.5 \%$ with an average value of $1.76 \%$ The organic matter in Site VII $(0.29 \%)$ were found low due to low organic carbon and highest in Site II (3.5\%) due to higher amount of humic substances present in the soil samples from decomposition of garbage wastes dumped on the soil and also due to addition of domestic wastes. Organic carbon level in most of the soil samples has been found poor in range.

Nitrogen is a major soil limiting nutrient elements and influence plant productivity. The nitrogen used by plants on dump materials comes from organic matter, fertilizer application and legumes plants [24]. In the present study, the available nitrogen content fluctuated between $90.24 \mathrm{~kg} / \mathrm{ha}$ to $98.64 \mathrm{~kg} / \mathrm{ha}$. with an average of $90.24 \mathrm{~kg} / \mathrm{ha}$. The minimum and maximum value recorded at Site V and Site II respectively. The higher values at Site II are due to addition of fertilizers and manures and lower value at Site V is attributed due to lower rates of mineralization process in the soil samples.

Phosphorus $(\mathrm{P})$ is an essential element classified as a macronutrient because of the relatively large amounts of phosphorus required by plants. Phosphorus is one of the three nutrients generally added to soils in fertilizers. It has been found by several scientists that the main roles of phosphorus in soils are the transfer of energy. A sufficient number of phosphorus availability for plants stimulates early plant growth and hastens maturity. So, Phosphorus is essential for plant growth in coal mining area and mismanagement of soil phosphorus can pose a threat to water quality and soil quality directly or indirectly ways. In the present study, available phosphorus was found in the range of 2.37 $\mathrm{kg} / \mathrm{ha}$ to $15.45 \mathrm{~kg} / \mathrm{ha}$. The phosphate content of the soil samples were recorded in low amount $(2.37 \mathrm{~kg} / \mathrm{ha})$ at Site II. This might be due to acidic nature of soil which restricted the microbial action activities resulting very poor mineralization process in the soil samples. Low phosphorus in soil is because of its presence in insoluble state or due to lack of organic matter in soil and high values recorded $(15.45 \mathrm{~kg} / \mathrm{ha})$ at Site II due to slightly alkaline nature of soil and addition of commercial fertilizers used for cultivation of crops.

Water holding capacity (WHC) of soil samples ranges from 28.01 to $43.48 \%$ with an average value was found $34.51 \%$. The minimum 28.01 was found at site VII and maximum $43.48 \%$ at site I. This is related to the particle size and texture because smaller particles had large surface area and hold maximum water content besides organic matter had also good affinity towards water [23].

The positive co-relation coefficient was observed between organic carbon with other parameters like $\mathrm{pH}$, electrical conductivity, organic matter, available phosphorus and available nitrogen. While as negative co-relation coefficient was found between maximum water holding capacity and bulk density $\left(r_{=} 0.95\right)$ as shown in Figure 3 because, soils 
Citation: Yaseen S, Pal A, Singh S, Skinder BM (2015) Soil Quality of Agricultural Fields in the Vicinity of Selected Mining Areas of Raniganj Coalfield India. J Environ Anal Toxicol 5: 269. doi:10.4172/2161-0525.1000269

Page 6 of 6

with high bulk density have a smaller volume of pore spaces. The similar correlation has also been reported by [17]. Bray curtis comparison shows that all the sites are similar: Similarity of $93.68 \%$ between sites VI and V, 96.7\% between Sites VIII and II, 93.8\% between VII and I, Site IV shows $92.45 \%$ similarity with Site VI and IV while as Site III showed similarity of $87.2 \%$ with other sites (Figure 4 )

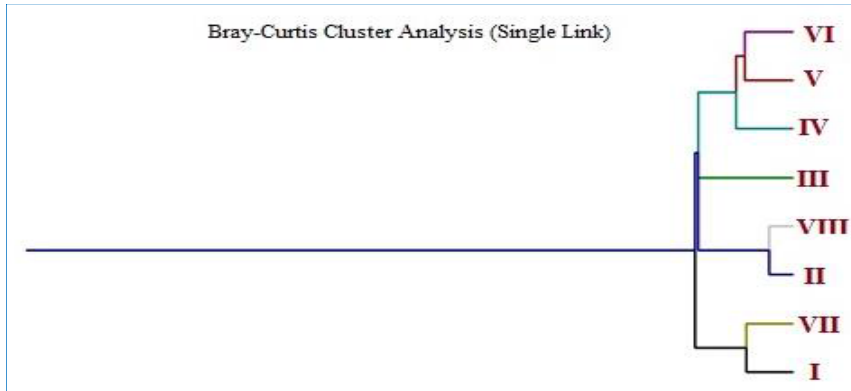

Figure 4: Bray curtis similarity analysis of different Sampling sites

\section{Conclusions}

It has been found that continuous coal mining activities in Raniganj coalfields has posed a severe threat to soil quality of nearby agriculture fields and has caused a long term impact to the important component (Soil) of natural ecosystem. Although the range of moisture content, bulk density, $\mathrm{pH}$ and electrical conductivity have been found moderate in the present study sites, where plants can show normal growth, but the concentration of organic carbon, organic matter, nitrogen and available phosphorus have been found low as compared to normal soils, thereby, indicated deterioration of soil quality, hence not found to be environmentally safe for plantation, vegetation and agricultural purposes.

\section{Acknowledgements}

The authors are highly thankful to Director, Central Institute of Mining and Fuel Research (CSIR) Dhanbad Jharkhand India for providing laboratory facilities to carry out the research study. The first author is indebted to Mr. K. K. Singh labaratory Assistant and Bipin kumar Mandol (Project associate) for helping during collection of soil samples.

\section{References}

1. Wu FC, Liu DL (2005) The Study about Theory and Practice of Mine Environment (in Chinese), Geology Press, Beijing: 1-49.

2. Shi $\mathrm{H}$ (2002) Study on the Bio-environment Issues and Strategy in Coal Mine in Shanxi (in Chinese). Chongqing Environmental Science 24: 11-12.

3. Sahadeb D, Mitra AK (2002) Reclamation of Mining-generated Wastelands at Alkusha-Gopalpur Abandoned Open Cast Project ,Raniganj Coalfield Eastern India. Environ Geol 43: 39-47.

4. Yaseen S Pal A, Singh S, Yousuf I (2012) A Study of physico-chemical characteristics of overburden dump materials from selected coal mining areas of Raniganj coal fields, Jharkhand, India. Global Journals of Science Frontier Research 12: 7-13.

5. Rai AK, Paul B (2011) Degradation of soil quality parameters due to coa mining operations in Jharia coalfield, Jharkhand, India. Journal of Advanced Laboratory Research in Biology 2: 64-69.

6. Jha AK, Singh JS (1992) Rehabilitation of mine spoils restoration of degraded land, Concepts and Strategies. 221- 254.

7. Ghose MK (1996) Damage of land due to coal mining and conservation of topsoil for land reclamation. Environment and Ecology 14: 466-468.

8. Dutta RK, Agrawal M (2002) Effect of tree plantations on the soil characteristics and microbial activity of coal mine spoil land. Tropical Ecology 43: 315-324.

9. Banerjee SK, Mishra TK, Singh AK, Jain A (2004) Impact of plantation on ecosystem development in disturbed coal mine overburden spoils. Journal Tropical Forest Science 16: 294-307.

10. Singh AN, Singh JS (2006) Experiments on ecological restoration of coal mine spoil using native trees in a dry tropical environment, India: a synthesis. New Forests 31:25-39.

11. Ekka JN, Behera N (2011) Species composition and diversity of vegetation developing on an age series of coal mine spoil in an open cast coal field in Orissa India. Tropical Ecology 52: 337-343.

12. Nelson DW, Sommers LE (1982) Methods of soil analysis, Part II, 9, American Society of Agronomy, Madison, USA 539 -579.

13. Bray R, Kurtz LT (1966) Determination of total, organic and available forms of phosphorus in soil. Soil Science 59: 39-45.

14. Keeney DR, Bremer JM (1966) Chemical index of soil nitrogen availability. Nature 211: 892-893.

15. Brady NC, Well RR (2002) The nature \& properties of soils, Pearson Education Ltd, New Delhi, India.

16. Maiti SK (2003) Handbook of methods in environmental studies, ABD Publishers, Jaipur, Rajasthan, India.

17. Chaudhari PR, Ahire DV, Ahire VD (2012) Correlation between Physico chemical properties and available nutrients in sandy loam soils of Haridwar. Journal of Chemical, Biological and Physical Sciences 2: 1493-1500.

18. Dhar B, Rolterdem B (1993) Environmental management and pollution control in mining industry, APH, New Delhi, India.

19. Rai AK, Paul B, Singh G ( 2010) A study on the Bulk density and its effect on the growth of selected grasses in coal mine overburden dumps, Jharkhand, India. International journal of environmental sciences 1: 677-684.

20. Tripathy DP, Singh G, Panigrahi DC (1998) Environmental effects of mine fires: A case study of Jharia coalfields, Proceedings of the Seventh National Symposium on Environment 204-205.

21. Saxena MM (1987) Environmental analysis water, soil and air, Agro Botanical Publication India.

22. Ghosh AB, Bajaj JC, Hassan R, Singh D (1983) Laboratory manual for soil and water testing 1ST Edition, Soil Testing Laboratory, Division of Soil Science and Agricultural Chemistry, IARI, New Delhi, India. 11- 17.

23. Donahue RL, Miller RW, Shickluna JC (1990) Soils: An introduction to soils and plant growth (5th edn) Prentice-Hall: 234.

24. Maiti SK, Karmakar NC, Sinha IN (2002) Studies on some physical parameters aiding biological reclamation of mine spoil dump a case study from Jharia coalfield. IME Journal 41:20- 23. 